\begin{tabular}{l|l} 
MILLOT'S HYDRAOLIC WHEEL. & loss of work. This wheel, nevertheless, utilizes about water and in the discharge, sinee it always utilizes the
\end{tabular}

In the setting up of a hydraulic wheel, the following 66 per cent of the work developed by the water. conditions always have to be satisfied: The water The Poncelet wheel is an undershot one, so modified without velocity. Compared with overshot wheels, it must be led from the head race with the least possible as to make it utilize a greater fraction of the work fur- presents a greater width of rim, that permits of taking loss of velocity; it must be made to act without shock; nished by the water, while at the same time allowing in three or four times more water. If we compare it and it must be discharged without velocity into the it the advantage of speed. Instead of flat buckets, it with breast wheels, or even with the Poncelet water tail race. Such conditions eannot be rigorously fulfilled has curved ones; and its performance announts to 60 wheel, we find that it does away with the construction with undershot wheels, as

the water loses a portion of its velocity before reaching the wheel, through friction against the sides of the race, and then, at the moment when it reaches one of the buckets, it suddenly loses its velocity and takes on that of the wheel and latter with considerable velocity. The performance of such a wheel rarely exceeds 25 per cent.

With the overshot wheel, provided it moves slowly, we obtain better results, since its motion, in which the water in the bucket participates, brings about a centrifugal force that modifies the form of the free surface of the liquid in each bucket. Such surface falls toward the interior of the wheel, and rises toward the exterior, so that the water tends to escape from the bucket before accomplishing its work. On another hand, if the water enters with slight velocity from the channel, it doe not produce any shock on running into the buckets, if the wheel is moving slowly, and, when the buckets empty, the water is deposited in the tail race without velocity.

Well arranged overshot

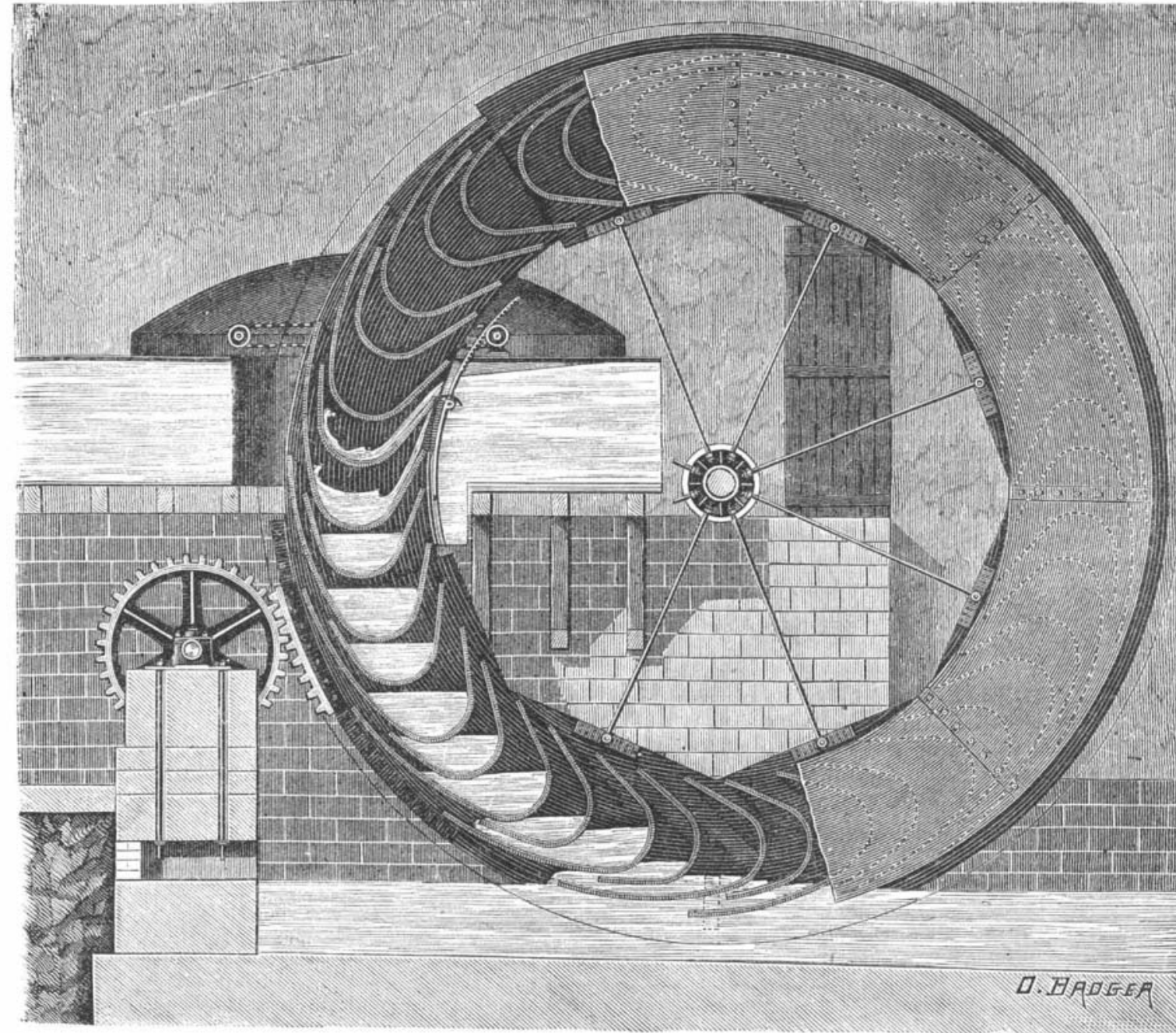

THE MILLOT-HAUVEL WATER WHEEL

and keeping in repair of wheel race, and it is not exposed to damage or accident from ice or the pas sage of a foreign body. The objection has been made to it that its diameter is nearly double the height of the fall, and that it is slow, thus multiplying gearings ; but the arrangement here illustrated and now used by Mr. Hauve shows that it is possible to obtain great speed on the driving shaft. As may be seen, the inclination of the buckets allows it to be im mersed to some depth without loss, and the slight velocity that is ascribed to it permits of following the current without meeting with resistance therein.

Mr. Hauvel employs iron plate buckets. The interior of the rim is toothed, thus rapidly multiplying the velocity of the driving shaft. The long shafts have been suppressed, and the heavy and cumbersome spoke have been replaced by simple bolted rods, that pass between the two distinct parts of the channel. The head race is thus divided into two portions of water that join each other on their fall into the bucket. This arrangement, which is simple, light, and strong, is very ingenious.

wheels utilize 75 per cent

of the motive work developed by the action of the per cent. The Sagebien wheel is a modification of the In order to facilitate the exit of the water, the exwater, especially with heads varying from ten to forty breast wheel, which, without being too wide, dis- ternal lips of the bucketsare made alternately long and feet.

With tharges a large volume of water, thus giving a bette acts does the breast wheel, the total weight of water that performar

wheel.
Such are the principal peculiarities of common water

short, so that the starting section is doubled. This receiver can, therefore, be applied to the utilization of a large discharge without the necessity of increasing its width out of measure. This arrangement does not prowater, and the race supports the other component or
part of such weight. It results from this that the
The accompanying figure represents a Millot wheel, wheel, while receiving the same quantity of work from as modified by Mr. C. Hauvel. This wheel keeps up a not fall into the race, but into the succeeding bucket. the water, is much less charged, and consequently the high performance, despite variations in the head of An official committee has found that the performance riction of its shaft upon the supports is less. But such advantages are counterbalanced by drawbacks due to that the play necessarily existing between the edges of the buckets and buce sions a loss of water, and also to the fact that the water, in running through the race, experiences quite a good deal of resistance.

To prevent too great a loss of water at this place, it beconles necessary to run the wheel with reater locity the do an do an oversh one, and the result is that the water leaves the wheel with a notable ve locity that carries witb it a

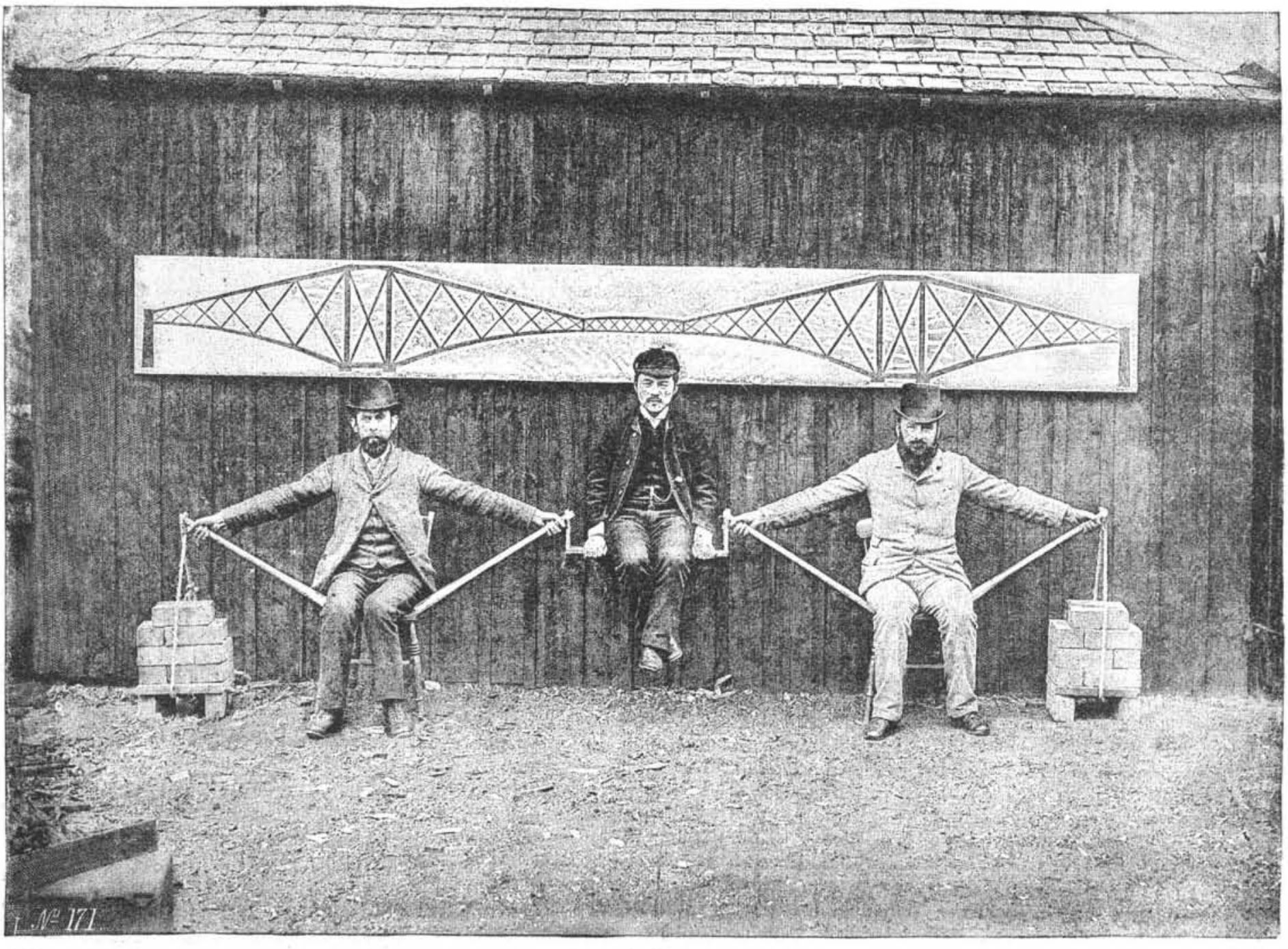

TEE PRINCIPLE OF THE FIRTH OF FORTH BRIDGE of this motor cent-Revu Industrielle.

HE FIRTH OF TORTH BY B. BA KER, $M$.

If we could transport one of the tubes of the great Britannia Bridge from the Menai Straits to the Forth, we should find it would span little more than one-fourth of the space to be spanned by each of the great Forth Bridge girders. And yet it was of this Britannia Bridgethat St e p h e nson, its engineer. thirty years ten inht I would lie toss. ing about seeking sleep in vain. The tubes filled my 
head. I went to bed with them and got up with them. compression. In the Forth Bridge you have to imagine echidna that has quite recently been discovered in In thegray of the morning, when I looked across Glou- the chairs placed a third of a mile apart, and the men's Northern New Guinea (Proechidna bruijni). This cucester Square, it seemed an immense distance across to heads to be 360 feet above the ground. Their arms rious animal in outward appearance resembles the the houses on the opposite side. It was nearly the are represented by huge steel lattice members, and the hedgehogs in its spine-covered body and the ant eater same length as the span of my tubular bridge !"

Our spans, as I have said, are each nearly four times as great as Stephenson's. To get an idea of their magnitude, stand in Piccadilly and look toward Buckingham Palace, and then consider that we have to span the entire distance across the Green Park, with a complicated steel structure weighing 15,000 tons, and to mediate pier or support. Consider also that our rail ages past. Indeed, I have evidence that even savages Worked by the powerful muscles with which the crea-
mathe level will be as high above the sea as the top of the when bridging in primitive style a stream of more than ture is provided, these are admirably adapted for

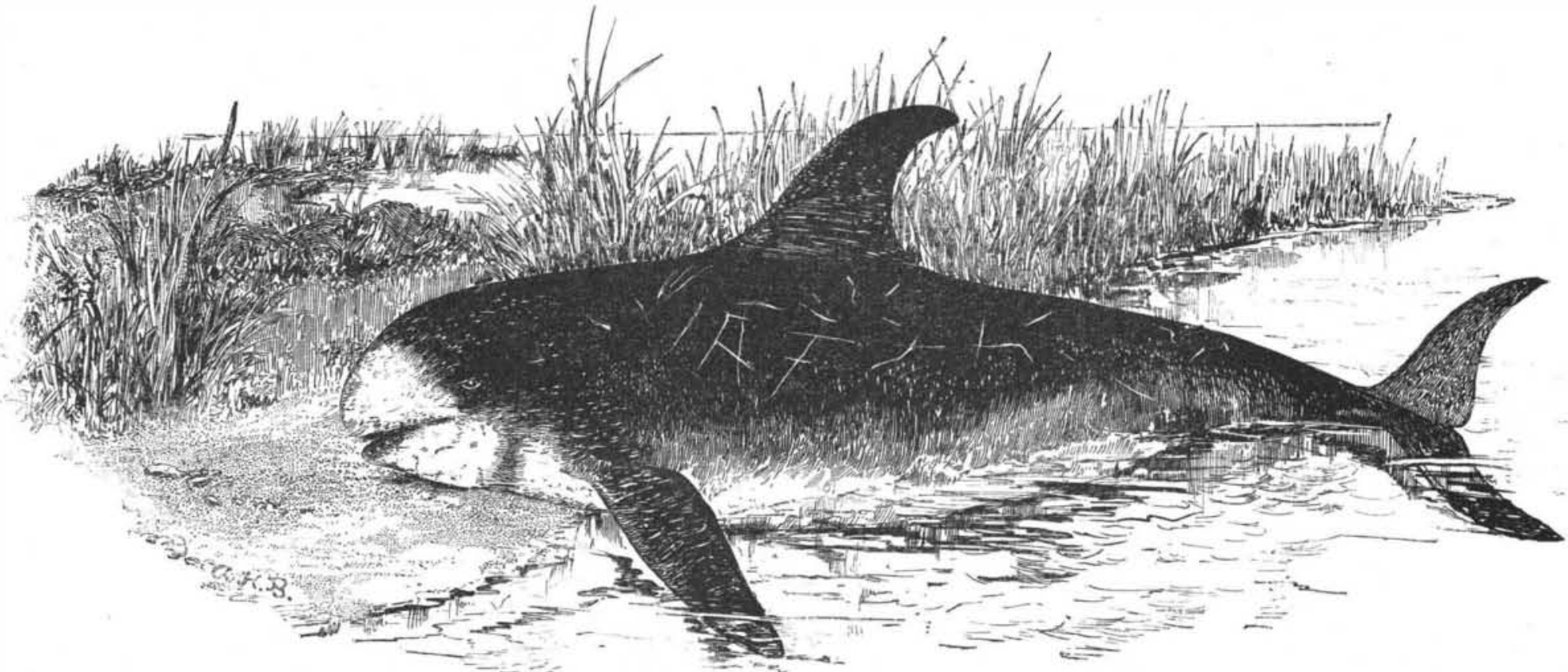

A TATTOOED WHALE.

dome of the Albert Hall is above street level, and that | ordinary width have been driven to the adoption of digging. The tail is rudimentary. Bruijn's echidna, the structure of our bridge will soar 200 feet yet above the cantilever and central girder systen, as we were which is over two feet in length, and is thus considera that level, or as high as the top of St. Paul's. The driven to it at the Forth. They would find the two bly larger than its Australian representative, is said by bridge would be a startling object indeed in a London cantilevers in the projecting branches of a couple of the natives to live in burrows in rocky ground.-Ir. landscape.

lt is not on account of size only that the Forth lash by grass ropes a central piece to the ends of their Bridge has excited so much Bridge has excited because it is of a previously little known type: I will $t$ not say novel, for there is nothing new under the sun. by exploring parties of engineers on the Canadian It is a cantilever bridge. One of the first questions Pacific and other railways, and in an old book in the by asked by the generality of visitors at the Forth is, Why do you call it a cantilever bridge? I admit that it is
not a satisfactory name, and that it only expresses half the truth, but it is not easy to find a short and satisfactory name for the type. A cantilever is simply another name for a bracket, but a reference to the diagram will show that the 1,700 feet openings of the Forth are spanned by a compound structure consisting of two brackets or cantilevers and one central girder. Owing to the arched form of the under side of the bridge, many persons hold the mistaken notion that the principle of construction is analogous to that of an arch.

In preparing for this lecture the other day; I had to consider how best to make a general audience appreciate the true nature and direction of the stresses on the Forth Bridge; and after consultation with some of our engineers on the spot, a living nodel of the structure was arranged as follows (see illustration): Two men sitting on chairs extended hairs extended heir a $\mathrm{rms}$ and upported the same by grasping sticks butting against the chairs. This represented the two double cantilevers. The central girder wa central girder was represented by a slung from one arm of each man and the anchorages by ropes extending from the other arms to a couple of piles of brick. of piles on When stresses ar brought on thi system by a load on the centra girder, the men's arms and the anchorage roper come into tension come into tension chair legs into

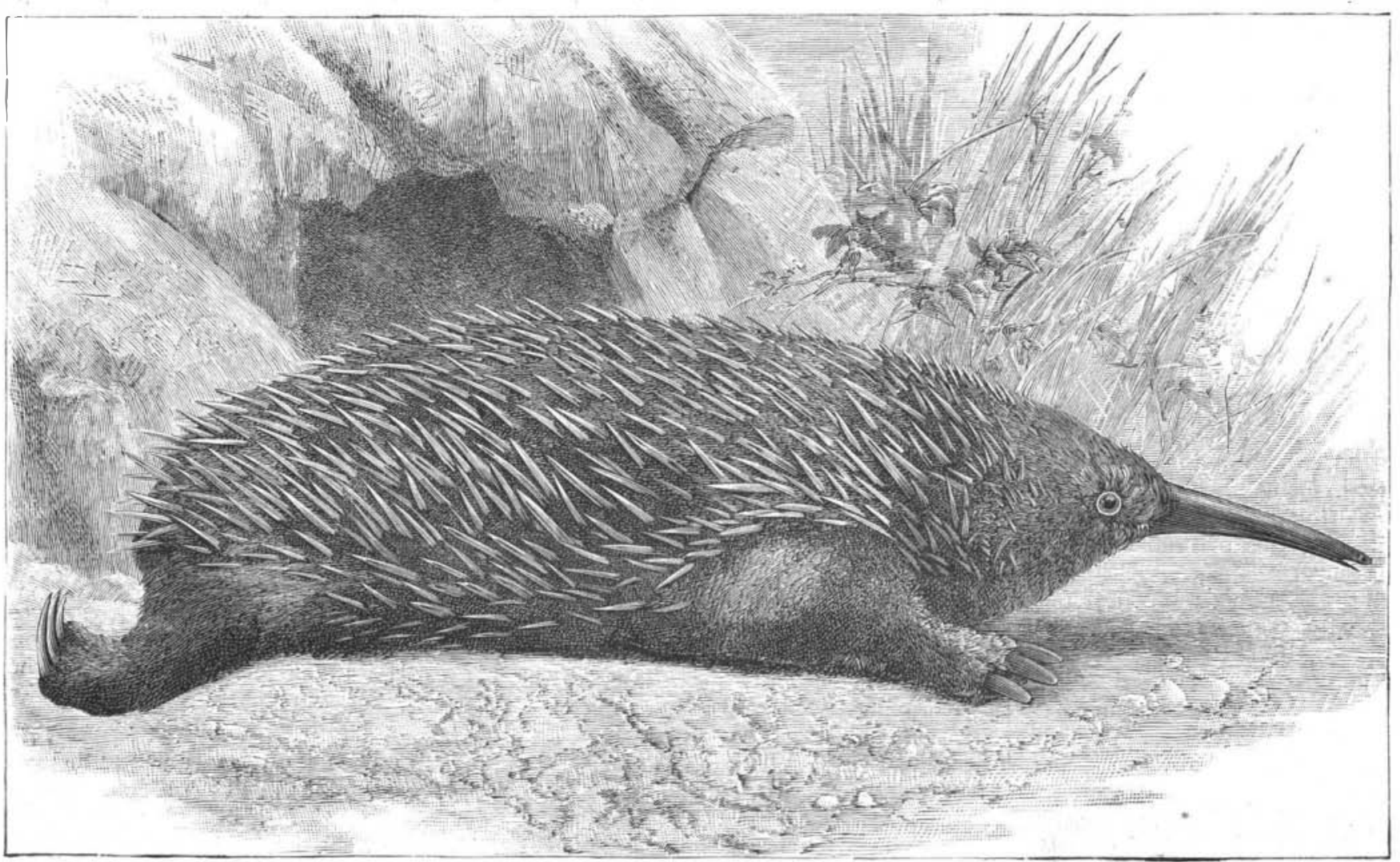

BRUIJN'S ECHIDNA (PROECHIDNA BRUIJND, NEW GUINEA ANT EATER.

\section{A TATTOOED WHALE.}

The accompanying sketch is taken from a cetacean bout twelve feet long, caught in a bluefish gill net the lighthouse board and life-saving service, in 1883 , members of these departments of the governinent are instructed to inform the commissioner of fisheries, at captured marine animals such as whales, porpoises, blackfish, and other forms of cetaceans.

Awong the papers forming the report of the fish commissioner for 1883 is a circular of instructions to fishermen and others on the coast, giving description and drawings of most of the known forms of cetaceans, and directions for the proper preservation of speciments, so affording sufficient knowledge to secure the safety of valuable and rare forms until they can be taken charge of by the necessary experts. BRUIJN'S ECHDNA (PROECHIDNA BRUIJNI), NEW
GUINEA ANT EATER. \begin{tabular}{c|c} 
BROIJN'S ECHDNA (PROECHIDNA BRUIJNI), NEW & $\begin{array}{c}\text { In consequence of the peculiarity of the animal } \\
\text { GUINEA ANT EATER. }\end{array}$ \\
captured at Nantucket, news of the fact was sent to \\
Our engraving shows the rare and extraordinary summer headquarters of the United States Fish
\end{tabular} Commission, at Wood's Holl, Mass., and the "whale," as the "whermen described it, was taken there, whence it will be sent, as a skeleton, to the $\mathrm{Nat}$ ion a $\mathrm{l} \mathrm{Mu}$ seum at Washington, to form a logical collection there. The ani$\mathrm{mal}$ is a grampus (Grampus grise us), a s p e cie which is somewhat co in m on throughout $t h$ North Atlantic. Several specimens have been taken, their capture being chiefly due to the habit of the species of skirting very near the shore, in pursuit of small fishes and minu te suxiface 